Board of Governors of the Federal Reserve System

International Finance Discussion Papers

Number 494

January 1995

\title{
GOVERNMENT BUDGET DEFICITS AND TRADE DEFICITS: ARE PRESENT VALUE CONSTRAINTS SATISFIED IN LONG-TERM DATA?
}

Shaghil Ahmed and John H. Rogers

Note: International Finance Discussion Papers are preliminary materials circulated to stimulate discussion and critical comment. Reference in publications to International Finance Discussion Papers (other than acknowledgement that the writer has had access to unpublished material) should be cleared with the author or authors. 


\begin{abstract}
We undertake tests of whether long term data from the U.S. and U.K. are consistent with the intertemporal government budget constraint and the intertemporal external borrowing constraint being satisfied in expected value terms, both individually and simultaneously. An historical perspective is appropriate for focusing on whether the present value constraints (PVCs) continue to hold in the face of unusual events, such as the outbreak of wars, that cause a structural break in the short-run dynamic behavior of the variables. This provides a very strong test of whether intertemporal budget constraints are satisfied. Our main results are: (i) the PVCs hold over the whole sample period; and (ii) the data are also consistent with the hypothesis that the PVCs continue to hold following events which cause a structural break in the short-run dynamics.
\end{abstract}




\section{Government Budget Deficits and Trade Deficits: \\ Are Present Value Constraints Satisfied in Long-Term Data? \\ Shaghil Ahmed and John H. Rogers ${ }^{1}$}

\section{Introduction}

"Let us be happy and live within our means, even if we have to borrer (sic) the money to do it with."

- Artemus Ward (1834-1867), Science and Natural History

Policymakers and academic economists have been keenly attracted to the issue of whether or not the economy is obeying its present value constraints (PVCs), i.e., whether the net present value of the government budget and external trade balances are zero, given the currently-expected course of policy. In the U.S., much of the interest in this topic stems from the debate about whether the government budget deficit and its "twin", the current account deficit are on a sustainable path.

In the academic literature, Hamilton and Flavin (1986) analyzed the feasibility of permanent government budget deficits (and spawned a series of papers reviewed below). Toward the paper's end (pg. 816), Hamilton and Flavin state, "One might want to admit the possibility of a change in regime in which the government budget had been expected to be balanced in present-value terms up until some date $t$ and only after that date was a permanent deficit introduced." They suggest 1981 as a candidate for a possible regime change date. However, they note, "Unfortunately, there are insufficient degrees of freedom to carry out such a test..."

In this paper we undertake precisely the experiment proposed by Hamilton and Flavin, choosing as candidates for possible regime changes dates corresponding to unusual events, such as wars, that change the short-run dynamic behavior of the variables. Focusing on the U.S. and U.K.,

\footnotetext{
${ }^{1}$ The authors are respectively: assistant professor of Economics at Penn State University and staff economist in the Division of International Finance of the Board of Governors of the Federal Reserve System. The views expressed in this paper are solely the responsibility of the authors and should not be interpreted as reflecting those of the Board of Governors of the Federal Reserve System or other members of its staff. We would like to thank Henning Bohn, Charles Engel, Steve Husted, Pierre Perron, Simon Potter, Mark Rush, Carl Walsh, and workshop participants at Cornell, Cal StateFullerton, Federal Reserve Bank of Dallas, Penn State, UCLA, University of Montreal, and Virginia Tech. Special thanks go to Jim Hamilton. Much of this project was completed while the second author was on the faculty Penn State University, from which he is currently on leave.
} 
we use data that covers a much longer time span than existing papers; for some series, our data begins in 1692. Given this long-term data set, several possible break dates occur at points in the sample for which sufficient degrees of freedom are available to determine statistically whether the PVCs continue to hold. Thus, motivated by Hamilton and Flavin we examine questions like: Does a structural break in the short-run dynamics caused, say, by an unusual increase in government spending also lead to the introduction of a long-term government budget deficit?

More specifically, we make three contributions to the literature. First, consider the long-term data set. Using a long span of data is appropriate in assessing whether the conditions implied by intertemporal budget constraints are met, because these conditions are only required to hold in the long run. Of course, when examining such a long span of data, one needs to be careful in relating the results on present value constraints to the sustainability of government policies. The finding that the PVCs hold over the whole sample period is not necessarily evidence that at some point in time agents were not considering the policies being followed to be unsustainable. That is why we also examine whether there are any structural breaks in the cointegrating vectors in the face of unusual events. The absence of a structural break in the cointegrating vectors is a necessary condition for agents to continue to believe, following these unusual events, that the PVCs are still satisfied. ${ }^{2}$ The stability test results are more than just for historical interest, as they can also be informative about the sustainability of current government policies, given the recent imbalances.

Second, we emphasize that the intertemporal budget constraints imply not only the existence of a long-run relationship between, for example, government expenditures and revenues, but specific

${ }^{2}$ In a related paper, using long term U.S. data, Bohn (1991a) estimates the contribution of subsequent tax increases and expenditure cuts in eliminating U.S. government budget deficits. He assumes stable time-series processes for government spending and taxes, and imposing the government's intertemporal budget constraint a priori, asks: If there is a shock to the government spending or tax equation, what adjusts subsequently to make the present value constraint hold? Our focus is different. Allowing for structural breaks in the time-series process generating government spending/taxation, which seems appropriate given the long-term data, we test for whether the present value constraints continue to hold in the post-split period. 
cointegrating vectors as well. Using recently developed techniques, we statistically test the hypothesis that the cointegrating vectors are as implied by the PVCs. Other studies attempting to do inference find that the cointegration relationships are not precisely determined [Trehan and Walsh (1988)].

Finally, besides considering the government and external PVCs individually, we also examine an additional economy-wide long term implication, which has not been exploited in previous work, that emerges when both PVCs are satisfied simultaneously.

In sections II and III, we review the literature and derive the cointegrating vectors implied by the PVCs. In section IV we present our methodology and the cointegration results, which are quite favorable to the PVCs holding over the entire sample period. In section V we investigate the stability of the cointegrating vectors. Section VI concludes.

\section{Related Literature}

Hamilton and Flavin (1986) consider whether perpetual government budget deficits are feasible. They develop the implication that if the present value of expected future surpluses is stationary, the stock of government debt should also be stationary. Using postwar U.S. data, they test for a unit root in the stock of government debt, the significance of a bubble term in their debt equation, and cross-equation restrictions across surplus and debt equations implied by the PVC. Hamilton and Flavin find no evidence that agents believe anything other than that the government will balance its budget in expected present value terms. Wilcox (1989) extends Hamilton and Flavin by allowing for a non-constant real interest rate and stochastic violations of the borrowing constraint. In contrast to Hamilton and Flavin, Wilcox finds that the currently expected course of U.S. fiscal policy is "unsustainable". He also finds some parameter instability and notes that results are sensitive to the lag length used in the unit roots tests. In addition, Kremers (1989) finds that U.S. fiscal policy is consistent with a bounded debt-GNP ratio, which supports Hamilton and Flavin's conclusions but contradicts those of Wilcox. 
Trehan and Walsh (1988) use longer term data than these other studies (1890-1983), and consider the U.S. government's borrowing constraint from the perspective of the implied cointegration between government expenditures and revenues. They find that the deficit inclusive of interest payments is stationary, or equivalently, government spending plus interest payments is cointegrated with government revenue. However, the authors are troubled by the fact that the unit root and cointegration tests sometimes give inconsistent results. They attribute this to the low power of the test [or to the possibility that interest rates are nonstationary (Trehan and Walsh (1991))], with the consequence that formal tests on the cointegrating vectors are unlikely to be informative. Hakkio and Rush (1991) argue that it is important to consider if government expenditures and revenues are cointegrated over sub-samples. They find no evidence of cointegration using quarterly data from 1975 to 1988 , and conclude that recent U.S. fiscal policy is unsustainable. Although such data is appropriate for analyzing the recent course of policy, a longer-term perspective is desirable.

The cirronic U.S. trade deficits af the 1980's have raised concerns about the sustainability of external deficits as well. Husted (1992) examines this issue by testing for cointegration between exports and imports plus interest payments abroad. For the whole sample, there is no evidence of cointegration, but an analysis of sub-samples supports cointegration if a structural break in 1983 is allowed. In common with several of the papers discussed earlier, Husted's paper is subject to small-sample problems because it focuses on recent data.

Much of the literature assumes a nonstochastic environment and relies on dynamic efficiency (which implies the real interest rate is greater than the growth rate of the economy) to meaningfully discuss intertemporal budget constraints. However, Abel et al (1989) point out that on average the real interest rate has been lower than the growth rate for many industrial economies; yet these authors also find that the condition required for dynamic efficiency - that capital income be greater than gross investment - holds for all countries considered. Because these two things can happen together only in 
a stochastic environment, Bohn (1991b) questions the appropriateness of PVC tests that depend on a nonstochastic environment and, in particular, a constant real interest rate.

\section{Present Value Constraints}

In light of the above discussion, we allow for a stochastic environment in developing our tests of intertemporal budget constraints. We use the following notation (all variables are in levels and expressed in real terms): $G_{t}=$ government spending (goods, services, transfers; not interest payments), $T_{t}=$ tax revenue, $I_{t}=$ gross investment, $C_{t}=$ consumption, $Y_{t}=$ output, $M_{t}=$ imports, $X_{t}=$ exports, $B_{t}^{f}=$ foreign debt, $B_{t}^{g}=$ government bonds, $r_{t}=$ real return on securities held between periods $t$ and $t+1, \Delta=$ first difference operator, $s_{t+j}=$ marginal rate of substitution (MRS) between consumption in period $t$ and $t+j=\left[\beta^{j} u^{\prime}\left(c_{t+j}\right)\right] / u^{\prime}\left(c_{t}\right), D_{t}=r_{t} B_{t}^{g}=$ interest payments on the national debt, $F_{t}=r_{t} B_{t}^{f}=$ net interest payments to foreigners, $E_{t}=$ rational expectation operator, conditional on knowledge of all variables dated $t$ and earlier.

Government Budget Balance: The government budget constraint for period $\mathrm{t}$ is given by:

$$
G_{t}-T_{t}+r_{t-1} B_{t-1}^{g}=B_{t}^{g}-B_{t-1}^{g}
$$

Equation (1) is the usual budget equation, stating that, in the absence of inflationary finance, a government budget deficit has to be financed by new debt creation. ${ }^{3}$ In the Technical Appendix (section A), we demonstrate that the sequence of period-by-period government budget constraints of the type (1) and the Euler equation from the consumer's optimization problem, $E_{t}\left[\left(I+r_{\nu}\right) s_{t+1}\right]=1$, lead to the following equation:

${ }^{3}$ Thus, we are abstracting from seignorage revenues. This is unlikely to matter in our applications, but may be very relevant in an extension to high inflation countries. 


$$
E_{t} \sum_{j=0}^{\infty}\left(s_{t+j} G_{t+j}\right)-E_{t} \sum_{j=0}^{\infty}\left(s_{t+j} T_{t+j}\right)+\left(1+r_{t-1}\right) B_{t-1}^{g}=\lim _{N \rightarrow \infty} E_{t}\left(s_{t+N} B_{t+N}^{g}\right)
$$

Eq. (2) is the standard intertemporal government budget constraint in expected value terms, except that future values are discounted by the marginal rate of substitution, $s_{t+j}$. (Note that it follows from the definition of $s_{t+j}$, that $s_{t}=1$.)

In order to derive our testable implications of the government balancing its budget intertemporally, take the first difference of (2), substitute for $\Delta B_{t-1}^{g}$ from (1) and simplify to get:

$$
\begin{gathered}
\Delta E_{t} \sum_{j=1}^{\infty}\left(s_{t+j} G_{t+j}\right)-\Delta E_{t} \sum_{j=1}^{\infty}\left(s_{t+j} T_{t+j}\right)+\left(G_{t}+r_{t-1} B_{t-1}^{g}-T_{t}\right) \\
=\lim _{N \rightarrow \infty} E_{t}\left(s_{t+N} B_{t+N}^{g}\right)-\lim _{N \rightarrow \infty} E_{t-1}\left(s_{t+N-1} B_{t+N-1}^{g}\right)
\end{gathered}
$$

The issue of interest, which we show is subject to empirical refutation under certain conditions, concerns the expected limit terms on the right-hand side of equations (2) and (3). Solvency requires that asymptotically the government cannot leave a debt that has a positive expected present value. Also, we rule out the government asymptotically leaving a debt with a negative expected present value on the grounds that the government is assumed not to allow anybody to run Ponzi schemes against it. Consequently, if the government satisfies its intertemporal budget constraint, the expected limit term in (2) will be zero, so that the sum of the current primary budget surplus, $\left(T_{t}-G_{t}\right)$, and the expected present discounted value of future primary surpluses will equal the amount needed to repay the principal and interest on the initial debt. When this condition holds, we say that the currently-expected paths of government spending and taxation are sustainable.

Note that even if the government debt is perfectly safe and has a constant rate of return $r$, it does not necessarily follow from $\lim _{N \rightarrow \infty} E_{t}\left[B_{t+N}^{g} /(1+r)^{N}\right]=0$ that the expected limit term in (2) is zero. As demonstrated by Bohn (1991b), even if the government debt were growing at less than the risk-free rate of return, with uncertainty the risk of a sharp decline in GNP may still make the limiting value of the expected debt-GNP ratio infinity. Hence, tests that directly equate the limiting 
condition given above to the present value constraint holding (such as those testing for a deterministic bubble term in the debt) are inapplicable in a stochastic environment. However, we will show that under certain conditions, which are quite plausible, tests of cointegration are still appropriate.

We demonstrate this in two steps. First, we show that if the limit terms on the right-handside of equation (3) are zero, a certain cointegrating relationship emerges. This means that cointegration is a necessary condition for the government's intertemporal budget constraint to hold. Then we show that, for a very general class of time series processes for the government debt, and under certain conditions, this same cointegrating relationship is also a sufficient condition for the present value constraint holding.

For the first step, suppose the following time series processes hold for $s_{t+j} G_{t+j}$ and $s_{t+j} T_{t+j}$ :

$$
\begin{aligned}
& \Delta s_{t+j} G_{t+j}=a_{G}+\eta_{G+j} \\
& \Delta s_{t+j} T_{t+j}=a_{T}+\eta_{t_{t+j}}
\end{aligned}
$$

where $\eta_{G}$ and $\eta_{T}$ are zero-mean stationary processes (the processes are not restricted in any other way) and $\mathrm{a}_{\mathrm{G}}$ and $\mathrm{a}_{\mathrm{T}}$ are constants. We show in the appendix (section B.1) that (4), (5) and the concept of rational expectations imply that all terms on the left hand side of (3) that involve a first difference are stationary. ${ }^{4}$ This in turn implies that, if the government present value constraint holds so that the

${ }^{4}$ Given that first differences of most macroeconomic variables have been found to be stationary, we regard the assumptions that $\Delta s_{t+j} G_{t+j}, \Delta s_{t+j} T_{t+j}$, etc. are stationary as being quite plausible. However, given that $s_{t+j}$ is an unobserved variable, these assumptions are not directly testable. This raises the question: If one is willing to assume only that $\Delta G_{t+j}, \Delta T_{t+j}$, etc. are stationary (which is testable using unit root tests), does the stationarity of the first differenced variables on the left hand side of (3) still follow. The answer is yes, under certain conditions. These conditions are: the marginal utility of consumption follows a random walk (which is a strict version of the permanent income hypothesis of consumption) and $\operatorname{cov}_{t}\left(s_{t+j}, Z_{t+j-k}\right)$ for $j \geq 1, k=0,1$ and $Z=G, T$ is constant over time, where $c o v$, represents the covariance conditioned on information available at period $t-i$. (See section B.2 of the appendix.) As an example, the covariance terms given above would be zero if the fiscal variables affected utility only in a separable way. 
limit terms on the right hand side of (3) are zero, the variables $\left(T_{t}, G_{t}, r_{t-1} B_{t-1}^{g}\right)$ are cointegrated with the cointegrating vector being $(1,-1,-1)$.

For the second step, i.e., to show sufficiency, consider the following class of time-series processes for the behavior of the government debt:

$$
B_{t}^{g}=\mu+B_{t-1}^{g}+\lambda^{t}+\varepsilon_{t}
$$

with $\varepsilon_{t}$ being a zero-mean stationary process. Since no other restrictions are imposed on $\varepsilon_{t}$, this is a very general process. If expected returns are constant and independently and identically distributed over time (which assumption is common in the asset prices literature) and if the risk-premium is constant in the steady state, then it is shown in the Technical Appendix (section C) that, if $|\lambda|<1$ in (6), the limit terms on the right hand side of (3) are zero. Further, from (1), $\left(T_{t}, G_{t}, r_{t-1} B_{t-1}^{g}\right)$ being cointegrated with cointegrating vector $(1,-1,-1)$ is equivalent to $\Delta B^{g}$, being stationary which, in turn, from (6) is equivalent to $|\lambda|<1$. The above cointegrating vector, for the class of debt processes given by (6) and under the conditions given is, thus, also a sufficient condition for the government's present value constraint to be satisfied. While these restrictions are not completely general, they are nevertheless quite plausible and go sufficiently beyond the assumption of a constant real rate of return that equals the rate of time preference every period.

For future discussion and estimation, it is convenient to write the cointegrating relationship that holds when stationary deviations from the long-run path have been set to zero as:

$$
T_{t}=\pi_{G}+G_{t}+r_{t-1} B_{t-1}^{g}
$$

where $\pi_{G}$ is a constant. Interpretation of the cointegrating relationship (7) is straightforward. Solvency requires that the budget deficit be stationary--total expenditures and revenues cannot drift too far apart over time--but does not necessarily imply that the national debt must eventually be paid off. For instance, by substituting (1) in (7), we can see that a positive mean value of $\Delta B_{t}^{8}$ is possible as long as it is matched by an equivalent negative value of $\pi_{G}$. This would imply that the drift in 
revenues $\left(a_{T}\right)$ exceed the drift in expenditure $\left(a_{G}\right)$ by exactly enough to finance the interest payments. What is ruled out is the "chain letter" phenomenon (Ponzi scheme) whereby the government forever accumulates debt at an excessive rate. Finally, the primary deficit may or may not be stationary (this depends on whether or not there is a unit root in interest payments).

External Budget Balance: Using the external period $t$ budget constraint, $M_{t}-X_{t}+r_{t-1} B_{t-1}^{f}=$ $\Delta B_{t}^{f}$, following exactly the same procedure as for the government's PVC above, and given that $\Delta s_{t+j}$ $M_{t+j}$ and $\Delta s_{t+j} X_{t+j}$ are stationary processes, we can show that the cointegrating relationship implied by external solvency is ${ }^{5}$ :

$$
X_{t}=\pi_{M}+M_{t}+r_{t-1} B_{t-1}^{f}
$$

The interpretation of eq. (8) parallels that of (7) exactly. The current account deficit (which includes interest payments) must be stationary, although it need not have a zero mean.

Economy-Wide Balance: An additional economy-wide relationship emerges when households internalize the government and external present value constraints. Substituting (7) and (8) into $Y_{\iota}=$ $C_{t}+I_{t}+G_{t}+X_{t}-M_{t}$, we get:

$$
Y_{t}=\left(\pi_{M}-\pi_{G}\right)+C_{t}+I_{t}+T_{t}+r_{t-1} B_{t-1}^{f}-r_{t-1} B_{t-1}^{g}
$$

The cointegrating relationship in eq. (9) implies that total savings and total investment must move together in the long run if both the government's and external PVCs are being satisfied.

\section{Data, Methodology, and Cointegration Results}

Our data consists of annual observations from the United States (variables prefixed by US) and United Kingdom (variables prefixed by UK) (see the Data Appendix for detailed sources):

\footnotetext{
${ }^{5} \mathrm{We}$ use the same symbol, $r$, for the interest rate on foreign debt as for government debt. This is for convenience only; in the empirical work we use the actual interest payments in each case. Also we abstract from net flows of foreign currency (changes in foreign currency reserves would be zero under flexible exchange rates).
} 
USG(1792-1992), UKG(1692-1992), UST(1792-1992), UKT(1692-1992), USX(1790-1992),

UKX(1697-1992), USM(1790-1992), UKM(1697-1992), USY(1889-1992), UKY(1830-1992),

USC(1889-1992), UKC(1830-1992), USI(1889-1992), UKI(1830-1992), USD(1792-1992),

UKD(1692-1992), USF(1889-1992), UKF(1830-1992).

Three issues with respect to the data deserve mention here: differences in the availability of the data within each country, heteroscedasticity (due to the length of the sample), and the distinction between real and nominal interest rates. First, data on UKF (USF) is available only back to 1830 (1889), while UKX and UKM (USX and USM) are available beginning in 1697 (1790). Because of this, we estimate two versions of the external constraint: (Version 1) dropping the variable $\mathrm{F}$ from the regression and using all observations on imports and exports and (Version 2) including $\mathrm{F}$ as a separate variabie and using fewer observations. Second, we use Phillips and Perron's (1988) Z( $\left(\mathrm{t}_{\alpha}^{\sim}\right)$ unit roots test because it is robust to heteroscedasticity. ${ }^{6}$ Third, the cointegrating vectors derived earlier ascure that the interest payments variables are expressed in real terms. Real net factor payments to foreigners are available, since we have data on GNP and GDP in real terms separately. However, for the government real interest payments, the proxy used is nominal interest payments deflated by the price level, which does not convert nominal into real interest rates. The consequence of this is that the coefficients on the $D$ variable in the cointegrating vectors we derived above need not necessarily be unity, but would be related to the ratio of the real to nominal interest rates; this should be borne in mind when interpreting the empirical results later.

Unit Roots: We employ Phillips-Perron (1988) and Perron (1989) tests for a unit root in each of the series used in (7)-(9). Phillips-Perron $Z\left(\tau_{\alpha}\right)$ test statistics reported in table 1 indicate a failure to reject the unit root null for the levels of each of the variables, but rejection for the first-differences. This is consistent with each variable being stationary in first-differences. The results of Perron's test

${ }^{6}$ Moreover, in addition to allowing for heteroscedasticity when estimating the cointegrating vectors, in an earlier version we also estimated the long-term relationships using per capita data. Our conclusions essentially remained unchanged. 
on the level of each series are also in table 1. Perron argues that, in the presence of structural breaks, conventional tests are biased toward finding unit roots. He develops unit root tests which allow for a one-time structural break. We applied Perron's test using several break dates and all three models for which he developed his test, but report only the results with his model B (which allows for a one-time exogenous change in the growth rate of a series). The unit root null is not rejected at the $5 \%$ significance level for any of the U.S. variables at any of the break dates (this is true for each of Perron's three models). Of the 27 cases reported for the U.K., we reject a unit root only twice at the $5 \%$ level and another time at the $10 \%$ level. In total, we looked at over 100 tests (including those not reported in table 1). In these, we find no rejections of the unit root null at the $1 \%$ level, 5 rejections at the $5 \%$ level and 9 rejections at the $10 \%$ level; this is about what we would expect for the given probabilities of type I error, if all our series contain unit roots.

Cointegration: The cointegrating vectors we estimate and do hypothesis testing on are ${ }^{7}$ :

$$
\begin{gathered}
T_{t}=\beta_{0}+\beta_{1} G_{t}+\beta_{2} D_{t}+v_{t} \\
X_{t}=\alpha_{0}+\alpha_{1} M_{t}+\alpha_{2} F_{t}+\varepsilon_{t} \\
Y_{t}=\gamma_{0}+\gamma_{1}\left(C_{t}+I_{t}\right)+\gamma_{2} T_{t}+\gamma_{3} F_{t}+\gamma_{4} D_{t}+u_{t}
\end{gathered}
$$

Cointegration among the variables appearing in each of (10)-(12) are necessary conditions for the present value constraints holding. We use Engle and Granger's (1987) ADF test to examine this. The test statistics in table 2 indicate that for the U.S. we reject the null of no cointegration at the $5 \%$ level in all cases. (Johansen's test also supports the presence of cointegration.)

\footnotetext{
${ }^{7} \mathrm{We}$ combine the variables $C$ and $I$ in (12) in order to cut down on the dimensionality of the system, thus preserving degrees of freedom.
} 
Stock-Watson Method: We use Stock and Watson's (1993) dynamic OLS procedure to estimate the cointegrating vectors because inference is particularly convenient with this method.

Before discussing results, we briefly describe the Stock-Watson method. Consider an n-dimensional vector of I(1) variables, $y_{t}$, whose first-differences are stationary stochastic processes with zero mean. If there are p cointegrating vectors among the $n$ elements of $y_{l}$, the system can be written:

$$
\begin{gathered}
\Delta y_{1 t}=u_{1 t} \\
y_{2 t}=\theta y_{1 t}+u_{2 t}
\end{gathered}
$$

where $y_{l t}$ is $(n-p) \times 1, y_{2 t}$ is $p \times 1, \theta$ is $p \times-(n-p)$, and $u_{l t}, u_{2 t}$ are zero mean stationary processes. With $u_{t}=\left(u_{l v}, u_{2 \nu}\right)^{\prime}$ stationary and Gaussian, the above system has the following triangular representation:

$$
\begin{gathered}
\Delta y_{1 t}=C_{11}(L) \varepsilon_{1 t} \\
y_{2 t}=\theta y_{1 t}+d(L) \Delta y_{1 t}+C_{22}(L) \varepsilon_{2 t}
\end{gathered}
$$

with $\varepsilon_{l b}, \varepsilon_{2 t}$ independent, and $d(L)$ a matrix of two-sided lag polynomials. Stock and Watson demonstrate that under fairly general conditions the OLS estimate of $\theta$ from (16)--labelled the dynamic OLS (DOLS) estimator--is asymptotically equivalent to MLE. ${ }^{8}$ Moreover, provided the moving average nature of the error term in (16) is accounted for, and the standard error is adjusted

${ }^{8}$ DOLS applied to equation (16) gives asymptotically ML estimates of $\theta$ if there are no restrictions between the parameters in $\mathrm{d}(\mathrm{L}), \mathrm{C}_{11}(\mathrm{~L})$ and $\mathrm{C}_{22}(\mathrm{~L})$. However, this condition will not be met in a model such as ours in which (13) and (14) would have an error-correction representation. If there are restrictions, there is a bias that arises in applying DOLS to (16) in that the true representation will have $d(L)$ being an infinite order two-sided polynomial, while in the empirical work it is being approximated by a finite order (say q) two-sided lag polynomial. However, Stock and Watson argue that the bias vanishes asymptotically if in the true representation $T$ goes to infinity faster than $\mathrm{q}^{3}$ goes to infinity. This is the condition required, and one which we have implicitly assumed in interpreting the Stock-Watson results as asymptotically ML estimates. 
for serial correlation, conventional inference on the null hypotheses of interest can be carried out on the cointegrating vectors. ${ }^{9}$

Estimates of the Cointegrating Vectors and Inference: The results from applying DOLS are reported in table $3 .^{10}$ We first discuss the results for the government's PVC. The slope terms $\beta_{I}$ and $\beta_{2}$ should be unity. For the U.S., the estimated cointegrating vector is $(1,0.93,1.06)$, while for the U.K it is $(1,1,0.82)$. In each case, intertemporal budget balance is not rejected at $5 \% .{ }^{11}$

Estimates of the external present value constraint indicate the cointegrating vector to be (1, $0.94)$ and $(1,0.77,0.56)$ for versions 1 and 2 respectively for the U.S. and $(1,0.87)$ and $(1,0.97$, 1.18) for versions 1 and 2 respectively for the U.K. The null hypothesis that the external PVC holds cannot be rejected for the U.S. or for version 1 for the U.K. at the $5 \%$ level. ${ }^{12}$ It is rejected for version 1 for the U.K., but recall that version 1 excludes interest payments, owing to lack of data. We conclude that, for both countries, there is strong evidence that the external borrowing constraint is satisfied over the entire sample period.

${ }^{9}$ Intuitively, including both leads and lags as a correction to the OLS cointegration regression borrows from Sims' (1972) work on causality tests. If a variable y Granger-causes another variable $\mathrm{x}$, then $\mathrm{y}$ can be expressed as a linear combination of past, present and future values of $\mathrm{x}$. This is because future values of $\mathrm{x}$ will contain information that is useful in predicting $\mathrm{y}$. Stock and Watson exploit this idea in proposing their correction. The correction asymptotically eliminates the effect of the endogenous regressor on the distribution of the OLS estimate of $\theta$, a problem that arises when there is Granger-causality running from the innovations in the dependent variable to the regressor.

${ }^{10}$ Throughout the paper when characterizing the short-run dynamics, we begin with a lag length of 5 and check the significance of the last lag and drop it if insignificant and then repeat the procedure for lag length 4 , etc. In one case (version 1 of the external constraint for the U.S.), it was clear that more than 5 lags were appropriate. Also, we use a fifth order MA correction in all cases.

"Recall that due to possible measurement error in the $D$ series the coefficient on this variable need not necessarily be unity in magnitude. However, in practice, in most cases (including the stability results presented later) the hypothesis of unit magnitude cannot be rejected.

${ }^{12}$ The results that for the U.S. the external PVC cannot be rejected for both versions 1 and 2 (i.e. with or without the inclusion of interest payments) are, strictly speaking, inconsistent with each other, given that all the variables are I(1). However, note that the two versions differ widely with respect to the sample period. 
Finally consider eq. (12), the economy-wide PVC, which represents the implied cointegrating relationship when both the external and government intertemporal budget constraints are satisfied. Eq. (12) implies that the slope terms $\gamma_{1}, \gamma_{2}, \gamma_{3}$ should be unity, while the slope term $\gamma_{4}$ should be -1 . The estimated cointegrating vector is $(1,1.07,1.94,-11.3,-7.09)$ for the U.S. and $(1,1.11,0.85$, $3.59,-2.28)$ for the U.K. These results represent mixed news for the economy-wide PVC. While the coefficient on $(C+I)$ is consistent with the PVC for both countries, the coefficients on $T$ and $D$ are insignificantly different from the predicted value only in the case of the U.K. and the sign of the coefficient on $F$ is opposite to the prediction for both countries. Thus the joint test for the government and external PVC holding simultaneously does not receive as strong support as the individual PVCs do, especially for the U.S.

\section{Stability}

Our findings above indicate that the government and external present value constraints hold over a long , uriod. As argued earlier, more powerful evidence for or against present value constraints can be obtained by examining whether there are structural breaks in the cointegrating vectors around times of unusual events such as wars or exchange rate regime switches.

For example, consider the government budget constraint and the outbreak of a war. This unusual event is very likely to lead to a structural break in the short-run dynamics of government spending and revenue, as well as, possibly, a change in the long-term drifts in these variables. But whatever these structural breaks are, revenue and, spending cannot drift too far apart in the long run if the government's intertemporal constraint continues to hold in expected value terms. Hence, the cointegrating vectors (i) being consistent with the government's PVC to begin with, and (ii) being stable across a particular break date are necessary conditions for agents to continue to believe that the government is not violating its intertemporal budget constraint. ${ }^{13}$ We now test this latter necessary

\footnotetext{
${ }^{13}$ It should be noted that it is not a sufficient condition, in general. Because agents expectations are not directly observed, if these expectations are not restricted in any way, there is always the possibility that at some particular structural break date agents regarded the government's fiscal
} 
condition, allowing the short run dynamics and the intercept term of the cointegrating vector to differ across war and nonwar years. ${ }^{14}$

Data limitations and degrees of freedom problems prevent us from looking at the stability of the economy-wide constraint. However, we do examine the stability of the long-term relationships implied by the government's PVC around wars and the external PVC around changes in exchange rate regimes. In the discussion below, we focus on the government's PVC only because, in the case of the external PVC, we could not find any structural breaks which could be attributed to a change in the exchange rate regime. (The stability results for the external PVC are available on request.)

To be more specific, the equation used to test the stability of the government's PVC is:

$$
\begin{aligned}
T_{t}= & \beta_{0}+\beta_{0}^{\prime} Z_{t}+\beta_{1} G_{t}+\beta_{1}^{\prime}\left(D U M_{t} \times G_{t}\right)+\beta_{2} D_{t}+\beta_{2}^{\prime}\left(D U M_{t} \times D_{t}\right) \\
& +d_{T I}(L) \Delta G_{t}+d_{T I}^{\prime}(L) \Delta\left(Z_{t} G_{t}\right)+d_{T 2}(L) \Delta D_{t}+d_{T 2}^{\prime} \Delta\left(Z D_{t}\right)+v_{t}
\end{aligned}
$$

where $Z_{t}$ is a dummy variable equal to 1 during war years, 0 otherwise and the variable $D U M_{t}$ is a split dummy variable equal to 1 in the year of and years after the split date, 0 otherwise. Major U.S. war years are defined to be 1861-65 (Civil War), 1917-19 (WWI) and 1941-46 (WWII). For the U.K., the major war years are 1702-13 (Spanish Succession), 1740-48 (Austrian Succession), 1756-63 (Seven Y'ears' War), 1775-83 (American Independence), 1793-1801, 1803-15 (Wars with France), 1854-56 (Crimean) 1899-02 (Boer), 1914-19 (WWI) and 1939-46 (WWII). We ran regressions like eq. (17) using every split date during and surrounding the war years for which enough degrees of freedom were available before and after the split date to be able to carry out the estimation. We then test whether the slope terms are as implied by the government's PVC before the split date $\left(\beta_{i}=1, i=1,2\right)$ and whether they are the same before and after the split date, both individually

policies as unsustainable but that, in time, these expectations were revised and the policies became sustainable again in expected value terms.

${ }^{14}$ The intercept terms are allowed to be different because, from the derivations in section 3 , the intercept term $\pi_{G}$ in equations like (6) is going to change when $a_{G}$ and $a_{T}$ in equations like (4) and (5) change. Also note that because cointegration is a long-run concept, the stability tests will require enough observations on either side of the break date to be valid. 
$\left(\beta_{i}{ }^{\prime}=0, i=1,2\right)$ and jointly $\left(\beta_{I}{ }^{\prime}=0=\beta_{2}{ }^{\prime}\right)$.

Table 4 provides the stability results for selected split dates. There are two main features of the U.S. results presented in panel A. First, the null hypotheses that the estimated coefficients in the cointegrating vectors are consistent with the government's PVC before the split date and are: unchanged at the split date, both individually and jointly, cannot be rejected at the $5 \%$ level, except for the case of WWII. Note that the results for WWII split dates may be subject to the same small sample problems we mentioned earlier with respect to other studies, since the number of observations after the split date may not be enough for valid estimates of the post-split long-term relationship. We conclude that, for the U.S., the idea of a stable cointegrating vector--which is a necessary condition for agents to continue to believe that the government's PVC is being satisfied in the face of a major break in the short run dynamics of the fiscal variables--cannot be rejected for those split dates where enough observations are available on either side of the split.

Second, even though the joint stability of the two slope coefficients in the cointegrating vector cannot be rejected, the p-values in the last column of panel A display a U-shaped pattern for both the Civil War and WWI and are consistently negatively related to the level of government expenditure. That is, the stability of the cointegrating vector comes closest to being rejected at the time when the intensity of the war is at its peak, which is generally also about the time when the outcome: of the war has become reasonably clear. While, admittedly, agents expectations are not directly observed, the pattern of p-values is nevertheless suggestive of the following interpretation: Agents' expectations of the future course of fiscal policy do vary with how much unusual movement there is in current government expenditure; however, these revisions in expectations are not inconsistent with the agents continuing to believe that the government will satisfy its intertemporal budget constraint (at least if we use a $5 \%$ significance level).

Now consider the stability results for the U.K. Britain fought numerous wars over the period, as indicated above. However, for brevity, we focus on results from three wars (American 
Revolution, Wars with France and WWI), the results from which are fairly typical. (The full set of results is available on request.) Table 4 (panel B) indicates that the stability of the cointegrating vector associated with the U.K. government's PVC cannot be rejected at the $5 \%$ level, as evidenced by the p-values reported in the last column of panel B. As in the case of the U.S., however, the strength of this result is strongly influenced by military events. For example, using the break dates $1811,1813,1816$, the respective $\mathrm{p}$-values are $(.09, .06, .13)$, while the corresponding percentage changes in real military spending are $(5.2,9.6,-41.1)$. These results are general; quite consistently, the p-values fall and then rise during the course of the various wars at the same time as government spending first rises and then falls.

These results from the U.K. should be qualified by noting that, while stability is supported by the p-values in panel $\mathrm{B}$, the coefficient on the government spending variable individually is different from unity in the pre-split period (column 1) and inconsistent with stability (column 2) for the American Revolution split dates as well as some split dates corresponding to the Napoleonic Wars and WWI. However, the null hypothesis of the coefficient on this variable being unity in the post split period $\left(\beta_{I}+\beta_{l}^{\prime}=1\right)$ generally cannot be rejected. Overall then, the stability results for the U.K. are somewhat inconsistent. They indicate that the cointegrating vector as a whole is stable over time, that the coefficient on the government interest payments variable is in line with the predicted value and also stable over time, and yet the coefficient on the government spending variable is in line with the government's PVC being satisfied for the post-split period, but not the pre-split period.

\section{Conclusion}

We have undertaken tests of whether U.S. and U.K. historical data are consistent with the intertemporal government budget and the intertemporal external borrowing constraints being satisfied in expected value terms. The long-term data set allows us to precisely test hypotheses on whether the cointegrating vectors are as implied by the present value constraints for the whole sample. In addition, it allows us to examine whether they are stable across time periods corresponding to unusual 
events--such as wars--that surely alter the short run dynamic behavior of the relevant variables. This stability is a necessary condition for agents to believe, even in the face of these unusual events, that the intertemporal budget constraints are going to continue to be satisfied. While this issue has been raised elsewhere in the literature, to our knowledge it has not been addressed.

In the case of both the U.S. and U.K.., we find strong evidence of the government and external present value constraints being satisfied over the whole sample period. However, the evidence on the additional economy-wide long-term relationship, implied by the government and external intertemporal constraints holding simultaneously, is not as strong.

In general, our stability results indicate that for those split dates where we have enough observations on either side of the split, the cointegrating vectors are found to be stable across time and consistent with the present value constraints holding for both the pre- and post-split periods. However, the U.K. stability results do not completely support this conclusion, since they are somewhat internally inconsistent. We also find that with respect to the government's coristraint, we come closest to rejecting stability of the cointegrating vectors when those split dates are chosen that correspond to the peak level of government spending during a given war. These results are not inconsistent with the idea that agents' expectations of the future course of fiscal policy are influenced by current unusual events, although the revised expectations are in line with the present value constraints continuing to hold in expected value terms.

The results of this paper suggest that despite the recent U.S. twin deficits problem, the currently expected future course of fiscal policy might still plausibly be regarded as being sustainable. However, it is clear, that to formally conclude this with any substantial degree of confidence--given the nature of the tests involved and the need for a long span of data that we have argued for--must await the availability of much more data. Finally, it would be interesting to see whether different conclusions are obtained when our stability tests are extended to countries such as Germany and France, which were specially war-ravaged and devastated by the major wars. 


\section{REFERENCES}

Abel, Andrew, Gregory Mankiw, Lawrence Summers, and Richard Zeckhauser (1989) "Assessing Dynamic Efficiency: Theory and Evidence," Review of Economic Studies 56, pp. 1-20.

Bohn, Henning (1991a) "Budget Balance Through Revenue or Spending Adjustments? Some Historical Evidence for the United States," Journal of Monetary Economics 27, pp. 333-360.

(1991b) "On Testing Sustainability of Government Deficits in a Stochastic Environment," The Wharton School.

Engle, R. F. and C. W. J. Granger (1987) "Cointegration and Error Correction: Representation, Estimation, and Testing," Econometrica 55, pp. 251-76.

Engle, Robert F. and Byung Sam Yoo (1987) "Forecasting and Testing in Co-Integrated Systems," Journal of Econometrics 35, pp. 143-59.

Hakkio, Craig S. and Mark Rush (1991) "Is the Budget Deficit Too Large?" Economic Inquiry.

Hamilton. James and Marjorie Flavin (1986) "On the Limitations of Government Borrowing: A Framework for Empirical Testing," American Economic Review 76, pp. 808-19.

Husted, Steven (1992) "The Emerging U. S. Current Account Deficit in the 1980's: A Cointegration Analysis," Review of Economics and Statistics 74, pp. 159-165.

Johansen, Soren (1988) "Statistical Analysis of Cointegration Factors," Journal of Economic Dynamics and Control 12, pp. 231-54.

Kremers, Jereon J. M. (1989) "U. S. Federal Indebtedness and the Conduct of Fiscal Policy," Journal of Monetary Economics 29, pp. 219-238.

Perron, Pierre (1989) "The Great Crash, the Oil Price Shock, and the Unit Root Hypothesis," Econometrica 57, pp. 1361-1401.

Phillips, Peter C. and Pierre Perron (1988) "Testing for a Unit Root in Time Series Regression," Biometrika 75, pp. 335-46.

Stock, James H. and Mark W. Watson (1993) "A Simple Estimator of Cointegrating Vectors in Higher Order Integrated Systems," Econometrica, 61, 783-820.

Trehan, Bharat and Carl E. Walsh (1988) "Common Trends, Intertemporal Budget Balance, and Revenue Smoothing," Journal of Economic Dynamics and Control 12, pp. 425-44.

(1991) "Testing Intertemporal Budget Constraints: Theory and Applications to U. S. Federal Budget and Current Account Deficits," Journal of Money, C.redit, and Banking 23, pp. 206-23.

Wilcox, David W. (1989) "The Sustainability of Government Deficits: Implications of the Present Value Borrowing Constraint," Journal of Money, Credit, and Banking 21, pp. 291-306. 


\section{DATA APPENDIX}

\section{SOURCES.}

I. UNITED STATES: (1) USG and USD - 1792-1970: (U.S. Bureau of the Census, 1976), series Y-457 and Y-461; 1971-1992: (U.S. Bureau of the Census, 1994). (2) UST - 1792-1939: (U.S. Bureau of the Census, 1976), series Y-335; 1940-1970: (U.S. Bureau of the Census, 1976), series Y343; 1971-1992: (U.S. Bureau of the Census, 1994). (3) USX and USM - merchandise exports and imports, 1791-1970: (U.S. Bureau of the Census, 1976), tables U-1 and U-8; 1971-1992: (U.S. Bureau of Economic Analysis, various issues). (4) USF, USY, USC, and USI - 1889-1929: (Kendrick, 1961); 1930-1970: (U.S. Bureau of the Census, 1976); 1971-1992: (U.S. Bureau of Economic Analysis, various issues). (5) USP - 1791-1888: Snyder-Tucker general price index, (U.S. Bureau of the Census, 1949), table L-14; 1889-1929: (Romer 1989, table 2); 1930-1970: (U.S. Bureau of the Census, 1976), table F 1-5; 1971-1992: (U.S. Bureau of Economic Analysis, various issues); is a GNP deflator from 1889-1989.

II. UNITED KINGDOM: (1) UKGTOT and UKD - 1692-1801: Mitchell, pp.578-580; 1802-1977: Mitchell, pp.587-595; 1978-1992: Central Statistical Office, table 16.4. Note that UKG = UKGTOT - UKD. (2) UKT - 1692-1801: Mitchell, pp.575-577; 1802-1977: Mitchell, pp.581-586; 1978-1992: Central Statistical Office, table 16.4. (3) UKX and UKM - merchandise exports and imports, 1697-1869: Mitchell and Deane, pp.279-283; 1870-1977: Mitchell, pp.871-873; 1978-1992: Central Statistical Office, table 13.1. (4) UKF, UKY, UKC and UKI - 1830-1977: Mitchell, pp.831835; 1978-1992: Central Statistical Office, table 14.1. (5) UKP - 1692-1979: Mitchell, pp.713-733; 1980-1992: Central Statistical Office, table 18.1; this series is a linking together of several (wholesale) price indices $(1900=1.00)$.

NOTES. (a) For both countries, data to construct the series $G, T, D, X$, and $M$ are nomiral data; the real magnitudes are constructed by dividing these nominal data by $\mathrm{P}$. The series $\mathrm{F}, \mathrm{Y}, \mathrm{C}$, and I are real magnitudes taken from the Income and Product Accounts as noted above. (b) Government spending includes transfer payments for both countries. (c) All fiscal variables are dated by the fiscal year, which usually does not correspond to the calendar year. (d) Re-exports consist of goods that were imported into the country only for the purpose of adding value to them and re-exporting. Thus we add them to exports (alternatively they could be subtracted from imports).

\section{REFERENCES FOR DATA APPENDIX.}

Central Statistical Office (1992 and 1994) Annual Abstract of Statistics, London.

Kendrick, John W. (1961) Productivity Trends in the United States. General Series, no.71.

Princeton, NJ: Princeton University Press (for NBER).

Mitchell, Brian R. (1988) British Historical Statistics (Cambridge University Press, Cambridge).

Mitchell, Brian R. and Phyllis Deane (1962) Abstract of British Historical Statistics (Cambridge University Press, Cambridge).

United States Bureau of Economic Analysis Survey of Current Business (Washington, DC).

United States Bureau of the Census (1949) Historical Statistics of the U.S. (Washington, DC). (1976) Statistical History of the United States (Washington, DC). (1992 and 1994) Statistical Abstract of the United States (Washington, DC). 


\section{TECHNICAL APPENDIX}

\section{A. Derivation of Equation (2) in the Text}

Update (1) by one period, multiply the result by $s_{t+1}$, apply the operator $E_{t}$ to both sides and use the intertemporal efficiency condition $E_{t}\left[\left(1+r_{t}\right) s_{t+1}\right]=1$ to show that:

$$
E_{t}\left(s_{t+1} G_{t+1}\right)-E_{t}\left(s_{t+1} T_{t+1}\right)+B_{t}^{g}=E_{t}\left(s_{t+1} B_{t+1}^{g}\right)
$$

Now update (1) in the text by two periods, multiply the result by $\mathrm{s}_{\mathrm{t}+2}$, apply $E_{t+1}$ to both sides, use the result that $\left.E_{t+1}\left[\left(1+r_{t+1}\right) s_{t+2}\right)\right]=s_{t+1}$ (proved below), then apply $E_{t}$ to both sides, use the law of iterated projections, and substitute for $E_{t}\left(s_{t+1} B^{g}{ }_{t+1}\right)$ from (A1). The result is:

$$
E_{t}\left(s_{t+1} G_{t+1}\right)+E_{t}\left(s_{t+2} G_{t+2}\right)-E_{t}\left(s_{t+1} T_{t+1}\right)-E_{t}\left(s_{t+2} T_{t+2}\right)+B_{t}^{g}=E_{t}\left(s_{t+2} B_{t+2}^{g}\right)
$$

Recursive substitutions of this type and substitution of $B^{g}$ from (1) lead to eq. (2) in the text.

To show that $\left.E_{t+1}\left[\left(1+r_{t+1}\right) s_{t+2}\right)\right]=s_{t+1}$ :

$$
\begin{aligned}
E_{t+1}\left[\left(1+r_{t+1}\right) s_{t+2}\right] & =E_{t+1}\left[\frac{\beta^{2} u^{\prime}\left(c_{t+2}\right)}{u^{\prime}\left(c_{t}\right)}\left(1+r_{t+1}\right)\right] \\
& =E_{t+1}\left[\frac{\beta u^{\prime}\left(c_{t+2}\right)}{u^{\prime}\left(c_{t+1}\right)}\left(1+r_{t+1}\right)\right] \frac{\beta u^{\prime}\left(c_{t+1}\right)}{u^{\prime}\left(c_{t}\right)} \\
& =1 \times s_{t+1}
\end{aligned}
$$

\section{B. Demonstrating that $P V C \Rightarrow$ Cointegration:}

B.1. Under the Assumptions that $\Delta s_{t+j} G_{t+j}$ and $\Delta s_{t+j} T_{t+j}$ are stationary: Note that 


$$
\begin{gathered}
\Delta E_{t} s_{t+j} G_{t+j}=E_{t} \Delta s_{t+j} G_{t+j}+\left(E_{t}-E_{t-1}\right) s_{t+j-1} G_{t+j-1} \\
=E_{t} \Delta s_{t+j} G_{t+j}+\left(E_{t}-E_{t-1}\right) \sum_{k=1}^{j} \eta_{G, t+j-k}
\end{gathered}
$$

where the second line in (B1) follows from eq. (4) in the text. Given that $\eta_{G, t+j}$ and $\Delta s_{t+j} G_{t+j}$ are stationary processes and expectations are rational, it follows that $\Delta E_{t} s_{t+j} G_{t+j}$ is stationary. Using an analogous argument with respect to $\Delta E_{\mathrm{r}} s_{\mathrm{t}+\mathrm{j}} T_{\mathrm{t}+\mathrm{j}}$ and the property that sums of $\mathrm{I}(0)$ variables are $\mathrm{I}(0)$ variables, it follows that all terms on the left hand side of (3) in the text that involve a first difference are stationary. It then immediately follows that if the government's PVC holds, implying the limit terms on the right hand side of (3) are zero, then $\left(T, G, r B^{8}\right)$ are cointegrated with cointegrating vector $(1,-1,-1)$.

B.2. Under the assumptions that $\Delta G_{t+j}$ and $\Delta T_{t+j}$ are stationary, $u^{\prime}(\cdot)$ is a random walk and $\operatorname{cov}_{t}\left(s_{t+j}, Z_{t+j-k}\right)$ for $j \geq 1, k=0,1$, and $Z=G, T$ is constant: Let

$$
\Delta G_{t+j}=a_{G}+\eta_{G, r+j}
$$

where $a_{G}$ is a constant and $\eta_{G}$ is a stationary process. Note that:

$$
\Delta E_{i t+j} G_{t+j}=E S_{t+j} \Delta G_{t+j}+\left(E_{t} s_{t+j} G_{t+j-1}-E_{t-1} s_{t+j-1} G_{t+j-1}\right)
$$

Now consider

$$
\begin{gathered}
E S_{t+j} G_{t+j-1}-E_{t-1} s_{t+j-1} G_{t+j-1}=E_{t} S_{t+j} E_{t} G_{t+j-1}-E_{t-1} s_{t+j-1} E_{t-1} G_{t+j-1} \\
+\operatorname{cov}_{t}\left(s_{t+j}, G_{t+j-1}\right)+\operatorname{cov}_{t-1}\left(s_{t+j-1}, G_{t+j-1}\right) \\
=k+\beta^{j}\left(E_{t}-E_{t-1}\right) G_{t+j-1} \\
=k+\beta^{j}\left(E_{t}-E_{t-1}\right) \sum_{k=1}^{j} \eta_{G, t+k-j}
\end{gathered}
$$

where $\mathrm{k}$ is a constant. The second line in (B4) follows from the assumption of constant covariances and the result that $E_{t} s_{t+j}=\beta^{j}=E_{t-1} s_{t+j-l}$, which follows from $u^{\prime}(\cdot)$ being a random walk. The 
third line follows from (B2). Plugging (B4) into (B3) and noting that $\eta_{G, t+j}, \Delta G_{t+j}$ are stationary processes and that $s_{t+j}$ is also a stationary process (which is also implied by $u^{\prime}(\cdot)$ being a random walk), it follows that $\Delta E_{t} s_{t+j} G_{t+j}$ is stationary. With an analogous derivation for the process governing taxes, the stationarity of all differenced terms on the left hand side of (3) follows. This, in turn, once again implies the cointegrating relationship described in section B.1. above, provided the limit terms on the right hand side of (3) are zero.

\section{Demonstrating that Cointegration $\Rightarrow P V C$ :}

$\left(T, G, r E^{g}\right)$ being cointegrated with cointegrating vector $(1,-1,-1)$ is equivalent to $\Delta B^{8}$ being stationary from (1) in the text, which is equivalent to $|\lambda|<1$ from (6) in the text. Now it remains to be shown that $|\lambda|<1$ also implies $\lim _{N \rightarrow \infty}\left[E_{t} s_{t+N} B^{g}{ }_{t+N}\right]=0$, under certain conditions, so that the present value constraint is satisfied.

Equation (6) in the text can be used to easily show that:

$$
s_{t+N} B_{t+N}^{g}=\mu N s_{t+N}+B_{t}^{g} s_{t+N}+\sum_{k=0}^{N} \lambda^{t+N-k} s_{t+N}+\sum_{k=0}^{N} \varepsilon_{t+N-k} s_{t+N}
$$

Assume that expected returns are constant and distributed i.i.d. over time. Then, $E_{\mathrm{t}}\left(1+r_{t+j}\right)$ $=\mathrm{R}>1, \forall j$ and $E_{\mathrm{t}} H_{t+N-I}=R^{N-I}$, where $H_{t+N-I}$ is the return from rolling over a one period bond for $N-1$ periods; i.e. $H_{t+N-I}=\left(I+r_{t}\right)\left(I+r_{t+l}\right) \ldots\left(I+r_{t+N-1}\right)$. Also assume that in the steady state, the risk premium is constant; specifically $\lim _{N \rightarrow \infty}\left[\operatorname{cov}\left(H_{t+N-l}, S_{t+N}\right)\right]=\sigma_{H s}$. Then, under the conditions given, the intertemporal efficiency condition for consumption, $E_{t}\left(H_{t+N-I,} s_{t+N}\right)=1$, implies the following: 


$$
\lim _{N \rightarrow \infty} E S_{t+N}=\lim _{N \rightarrow \infty}\left[\frac{1-\operatorname{cov}\left(H_{t+N-1}, S_{t+N}\right)}{R^{N-1}}\right]=\frac{1-\sigma_{H s}}{\lim _{N \rightarrow \infty}\left[R^{N-1}\right]}=0
$$

Given (C2) and the properties of $\varepsilon$, the limiting values of the second and fourth terms on the right hand side (RHS) in (C1) are obviously zero. Using L'Hopital's rule, (C2) can also be easily shown to imply that the limiting value of the first term on the RHS of (C1) is also zero. Further, if $|\lambda|<$ 1, (C2) also implies that the limiting value of the second term on the RHS of (C1) is zero. With all these four limit terms being zero, (C1) implies $\lim _{N \rightarrow \infty} E_{t} s_{t+N} B_{t+N}^{g}=0$. 
Table 1; Unit Roots Tests

A. Phillips-Perron Tests

\begin{tabular}{||l|c|c|c|c|c|c|c|c||}
\hline \hline Variable & UST & USG & USD & USX & USM & USF & USCI & USY \\
\hline level & 2.32 & -0.15 & 7.66 & 1.72 & 3.82 & -2.64 & 0.28 & -0.13 \\
\hline 1st-diff. & $-10.3^{* *}$ & $-7.75^{* *}$ & $-5.41^{* *}$ & $-8.46^{* *}$ & $-12.9^{* *}$ & $-10.1^{* *}$ & $-8.30^{* *}$ & $-6.11^{* *}$ \\
\hline \hline Variable & UKT & UKG & UKD & UKX & UKM & UKF & UKCI & UKY \\
\hline level & 2.90 & 1.11 & 0.11 & 5.42 & 4.85 & -3.34 & 1.47 & 1.52 \\
\hline 1st-diff. & $-11.3^{* *}$ & $-10.3^{* *}$ & $-11.6^{* *}$ & $-11.2^{* *}$ & $-10.9^{* *}$ & $-14.0^{* *}$ & $-6.50^{* *}$ & $-9.96^{* *}$ \\
\hline
\end{tabular}

B. Perron Tests

\begin{tabular}{||l|c|c|c|c|c|c|c|c||}
\hline Break/Var. & UST & USG & USD & USX & USM & USF & USCI & USY \\
\hline 1861 & 2.04 & -0.62 & -0.89 & 1.00 & 2.02 & - & - & - \\
\hline 1917 & 1.46 & -3.32 & -1.97 & -0.97 & 0.27 & -3.30 & -0.46 & -0.71 \\
\hline 1941 & 1.65 & $-3.92^{\prime \prime}$ & -2.89 & -2.33 & -2.16 & -3.18 & -2.54 & -1.41 \\
\hline 1973 & 2.38 & -1.02 & -2.18 & -1.64 & 2.50 & -3.45 & 1.78 & 0.65 \\
\hline \hline Break/Var. & UKT & UKG & UKD & UKX & UKM & UKF & UKCI & UKY \\
\hline 1812 & 0.82 & 0.32 & -1.46 & -- & -- & -- & - & - \\
\hline 1914 & -3.84 & -3.14 & $-4.48^{*}$ & -0.15 & -0.06 & -1.22 & -0.49 & -1.86 \\
\hline 1939 & $-4.18^{*}$ & -3.45 & -3.10 & -3.42 & -2.92 & -3.14 & $-4.05^{\#}$ & -3.24 \\
\hline 1973 & -0.51 & -1.70 & -2.04 & 2.49 & 1.77 & -1.94 & 1.54 & 2.16 \\
\hline
\end{tabular}

Notes: Entries in part A represent the Phillips-Perron (1988) $\mathrm{Z}\left(\tau_{\alpha}\right)$ test statistic for the unit root null hypothesis. In part B are results from estimating Perron's (1989) model B for the break date noted. For all tests, a ${ }^{* *}, *$, \# indicates rejection of the unit root null at $1 \%, 5 \%$, and $10 \%$, respectively. A lag length of 5 is used in all tests. $\mathrm{CI}$ refers to the variable $(C+I)$. 
Table 2; Augmented Dickey Fuller Tests for Cointegration

\begin{tabular}{||l|c|c||c|c|c||}
\hline \hline System (U.S.) & ADF Stat. & Lags & System (U.K.) & ADF Stat. & Lags \\
\hline T, G, D & $-4.89^{* *}$ & 5 & T, G, D & $-3.67^{*}$ & 5 \\
\hline X, M & $-4.56^{* *}$ & 5 & X, M & $-3.45^{*}$ & 5 \\
\hline X, M, F & $-5.13^{* *}$ & 5 & X, M, F & $-3.96^{*}$ & 5 \\
\hline Y, CI, T, F, D & $-3.69^{\mathrm{a}}$ & 5 & Y, CI, T, F, D & $-3.01^{\mathrm{a}}$ & 5 \\
\hline Y, CI, T, F, D & $-5.01^{* *}$ & 1 & Y, CI, T, F, D & $-4.81^{*}$ & 1 \\
\hline
\end{tabular}

Notes: Rejection of the no cointegration null hypothesis at $(1 \%, 5 \%, 10 \%)$ is denoted by (**, *, \#). (a) For this system, lags 2-5 are insignificant, so results are also reported for a lag length of 1 .

Table 3; Estimates of the Cointegrating Vectors

\begin{tabular}{|c|c|c|c|}
\hline $\begin{array}{l}\text { System [U.S.] } \\
\text { (sample period) }\end{array}$ & $\begin{array}{l}\text { Estimated Vector } \\
\text { (std. error) }\end{array}$ & $\begin{array}{l}\text { Variables in } \\
\text { SR Dynamics }\end{array}$ & $\begin{array}{l}\text { Lead / L.ag } \\
\text { Length }\end{array}$ \\
\hline $\begin{array}{c}\text { T, G, D } \\
(1795-1990)\end{array}$ & $\begin{array}{r}1,0.93,1.06 \\
(.08)(.51)\end{array}$ & G, D & 2 \\
\hline $\begin{array}{l}\mathrm{X}, \mathrm{M} \\
(1800-1985)\end{array}$ & $\begin{array}{r}1,0.94 \\
(.11) \\
\end{array}$ & $\mathbf{M}$ & 7 \\
\hline $\begin{array}{l}\mathrm{X}, \mathrm{M}, \mathrm{F} \\
(1895-1988)\end{array}$ & $\begin{array}{r}1,0.77,0.56 \\
(.15)(.59)\end{array}$ & $\mathrm{M}, \mathrm{F}$ & 4 \\
\hline $\begin{array}{l}\text { Y, CI, T, F, D } \\
(1892-1990)\end{array}$ & $\begin{array}{r}1,1.07,1.94^{*},-11.3^{*},-7.09^{*} \\
(.15)(.44)(5.51)(2.59)\end{array}$ & $\mathrm{CI}, \mathrm{T}, \mathrm{F}, \mathrm{D}$ & 2 \\
\hline $\begin{array}{l}\text { System [U.K.] } \\
\text { (sample period) }\end{array}$ & $\begin{array}{c}\text { Estimated Vector } \\
\text { (std. error) }\end{array}$ & $\begin{array}{l}\text { Variables in } \\
\text { SR Dynamics }\end{array}$ & $\begin{array}{l}\text { Lead / Lag } \\
\text { Length। }\end{array}$ \\
\hline $\begin{array}{l}\mathrm{T}, \mathrm{G}, \mathrm{D} \\
(1698-1987)\end{array}$ & $\begin{array}{r}1,0.996,0.82 \\
(.12)(.18)\end{array}$ & G, D & 5 \\
\hline $\begin{array}{l}X, M \\
(1699-1987)\end{array}$ & $\begin{array}{l}1,0.87^{*} \\
(.04)\end{array}$ & M & 5 \\
\hline $\begin{array}{c}\mathrm{X}, \mathrm{M}, \mathrm{F} \\
(1836-1987)\end{array}$ & $\begin{array}{r}1,0.97,1.18 \\
(.03)(.21)\end{array}$ & $\mathrm{M}, \mathrm{F}$ & 5 \\
\hline $\begin{array}{l}\text { Y, CI, T, F, D } \\
(1833-1990)\end{array}$ & $\begin{array}{r}1,1.11,0.85,-3.59^{*},-2.28 \\
(.09)(.26)(0.92)(0.71)\end{array}$ & $\mathrm{CI}, \mathrm{T}, \mathrm{F}, \mathrm{D}$ & 2 \\
\hline
\end{tabular}

Notes: $\mathrm{A}\left({ }^{*}\right)$ indicates that the estimated coefficient is significantly different from its predicted value. 
Estimated eqn:

Table 4; Selected Stability Tests

$$
\begin{aligned}
& T_{t}=\beta_{0}+\beta_{0}^{\prime} Z_{t}+\beta_{I} G_{t}+\beta_{l}^{\prime}\left(D U M_{t}^{*} G_{l}\right)+\beta_{2} D_{t}+\beta_{2}^{\prime}\left(D U M_{t}^{*} D_{\nu}\right. \\
& +d_{T I}(L) \Delta G_{t}+d_{T I}^{\prime}(L) \Delta\left(G_{t}^{*} Z_{l}\right)+d_{T 2}(L) \Delta D_{t}+d_{T 2}^{\prime}(L) \Delta\left(D_{t}^{*} Z_{\nu}\right)+v_{t}
\end{aligned}
$$

A. U.S. Results

\begin{tabular}{||c|c|c|c|c|c||}
\hline Split Date & $\begin{array}{c}\beta_{1} \\
(\text { s.e. })\end{array}$ & $\begin{array}{c}\beta_{1}^{\prime} \\
(\text { s.e. })\end{array}$ & $\begin{array}{c}\beta_{2} \\
(\text { s.e. })\end{array}$ & $\begin{array}{c}\beta_{2}^{\prime} \\
(\text { s.e. })\end{array}$ & $\begin{array}{c}\mathrm{H}_{0}: \beta_{1}^{\prime}=\beta_{2}^{\prime}=0 \\
\text { (p-value })\end{array}$ \\
\hline 1862 & $3.58(2.67)$ & $-2.70(2.68)$ & $-8.38(28.3)$ & $9.33(28.3)$ & .45 \\
\hline 1863 & $7.24^{*}(2.90)$ & $-6.36^{*}(2 . .91)$ & $-14.6(34.3)$ & $15.5(34.3)$ & .09 \\
\hline 1915 & $2.18(0.86)$ & $-1.30(0.87)$ & $0.55(1.69)$ & $0.38(1.68)$ & .30 \\
\hline 1917 & $2.08(0.83)$ & $-1.20(0.85)$ & $0.85(1.57)$ & $0.08(1.60)$ & .34 \\
\hline 1919 & $1.44(0.32)$ & $-0.55(0.31)$ & $2.31(1.92)$ & $-1.39(1.86)$ & .10 \\
\hline 1921 & $1.41(0.34)$ & $-0.52(0.33)$ & $0.76(2.41)$ & $0.15(2.33)$ & .23 \\
\hline 1942 & $0.88(0.34)$ & $-0.02(0.32)$ & $-1.88(2.18)$ & $2.84(2.20)$ & .13 \\
\hline 1943 & $0.68(0.27)$ & $0.19(0.27)$ & $-0.91(1.78)$ & $1.85(1.84)$ & .04 \\
\hline 1944 & $0.19(0.10)$ & $0.76^{*}(0.12)$ & $2.95^{*}(0.63)$ & $-2.29^{*}(0.69)$ & .00 \\
\hline
\end{tabular}

B. U.K. Results

\begin{tabular}{||l|c|c|c|c|c||}
\hline \hline Split Date & $\begin{array}{c}\beta_{1} \\
\text { (s.e. })\end{array}$ & $\begin{array}{c}\beta_{1}^{\prime} \\
(\text { s.e. })\end{array}$ & $\begin{array}{c}\beta_{2} \\
(\text { s.e. })\end{array}$ & $\begin{array}{c}\beta_{2}^{\prime} \\
(\text { s.e. })\end{array}$ & $\begin{array}{c}\mathrm{H}_{0}: \beta_{1}^{\prime}=\beta_{2}^{\prime}=0 \\
\text { (p-value) }\end{array}$ \\
\hline 1776 & $6.25^{*}(2.59)$ & $-5.30^{*}(2.58)$ & $-3.88(3.84)$ & $4.85(3.85)$ & .11 \\
\hline 1782 & $6.94^{*}(2.86)$ & $-6.00^{*}(2.85)$ & $-4.08(3.98)$ & $5.08(3.68)$ & .09 \\
\hline 1783 & $6.77^{*}(2.79)$ & $-5.82^{*}(2.78)$ & $-4.01(3.92)$ & $5.00(3.62)$ & .10 \\
\hline 1811 & $7.21^{*}(2.88)$ & $-6.27^{*}(2.87)$ & $-4.89(3.24)$ & $5.90(3.05)$ & .09 \\
\hline 1813 & $7.59^{*}(2.83)$ & $-6.64^{*}(2.82)$ & $-5.30(3.30)$ & $6.29(3.11)$ & .06 \\
\hline 1816 & $5.77(2.54)$ & $-4.81(2.53)$ & $-3.32(3.06)$ & $4.25(2.86)$ & .13 \\
\hline 1914 & $0.91(0.25)$ & $0.06(0.25)$ & $1.78(0.68)$ & $-0.88(1.01)$ & .65 \\
\hline 1917 & $0.71(0.23)$ & $0.25(0.20)$ & $2.25(069)$ & $-1.32(0.94)$ & .29 \\
\hline 1918 & $0.51^{*}(0.22)$ & $0.43^{*}(0.19)$ & $2.46(0.69)$ & $-1.47(0.95)$ & .07 \\
\hline
\end{tabular}

NOTES: $Z_{t}$ is a dummy variable equal to 1 during war years, 0 otherwise; DUM, is a dummy variable equal to 1 in the year of and years after the split date, 0 otherwise. The lead/lag length is employed is the same as in Table 3. The abbreviation s.e. represents standard error. The notation* indicates estimate is statistically different from its predicted value and p-value refers to the marginal significance level for which the $\chi^{2}$ statistic just fails to accept the null hypothesis. 


\section{International Finance Discussion Papers}

IFDP

Number

494

493

491

490

489

488
Titles

Author(s)

$\underline{1995}$

Government Budget Deficits and Trade Deficits:

Are Present-Value Constraints Satisfied in

Long-Term Data?

Real Shocks and Real Exchange Rates in Really Long-Term Data

1994

Loss Aversion in a Consumption/Savings Model

Terms-of-Trade Uncertainty and Economic Growth:

Are Risk Indicators Significant in Growth

Regressions

itics, Economics, and Investment: Explaining

Plant and Equipment Spending by U.S. Direct

Investors in Argentina, Brazil, and Mexico

On The Dynamic Properties of Asymmetric

Models of Real GNP

A distributed block approach to solving

near-block-diagonal systems with an application

to a large macroeconometric model

David Bowman

Deborah Minehart

Matthew Rabin

Enrique G. Mendoza

Guy V.G. Stevens

Allan D. Eirunner

Jon Faust

Ralph Tryon

Neil R. Ericsson

Michael P. Leahy

Bank Position
Movements

Technological Progress and Endogenous Capital Depreciation: Evidence from the U.S. and Japan

Robert Dekle

John Ammer

Allan D. Eirunner

Explaining Foreign Exchange Trading Profits

Susanto Basu

Constant Returns and Small Markups in U.S.

John G. Fernald

Please address requests for copies to International Finance Discussion Papers, Division of International Finance, Stop 24, Board of Governors of the Federal Reserve System, Washington, D.C. 20551. 


\section{International Finance Discussion Papers}

IFDP

Number

482

481

480

479

478

477

476

475

474

473

472

471

470

469
Titles

$\underline{1994}$

The Real Exchange Rate and Fiscal Policy During the Gold Standard Period: Evidence from the United States and Great Britain

The Debt Crisis: Lessons of the 1980s for the 1990s

Who Will Join EMU? Impact of the Maastricht Convergence Criteria on Economic Policy Choice and Performance

Determinants of the 1991-93 Japanese Recession: Evidence from a Structural Model of the Japanese Economy

On Risk, Rational Expectations, and Efficient Asset Markets

Finance and Growth: A Synthesis and Interpretation of the Evidence

Trade Barriers and Trade Flows Across Countries and Industries

The Constancy of Illusions or the Illusion of Constancies: Income and Price Elasticities for U.S. Imports, 1890-1992

\section{The Dollar as an Official Reserve Currency under} EMU

Inflation Targeting in the 1990s: The Experiences of New Zealand, Canada, and the United Kingdom

International Capital Mobility in the 1990s

The Effect of Changes in Reserve Requirements on Investment and GNP

International Economic Implications of the End of the Soviet Union

International Dimension of European Monetary Union: Implications For The Dollar $\underline{\text { Author(s) }}$

Graciela L. Kaminsky

Michael Klein

Graciela L. Kaminsky

Alfredo Pereira

R. Sean Craig

Allan D. Brunner

Steven B. Kamin

Guy V.G. Stevens

Dara Akbarian

Alexander Galetovic

Jong-Wha Lee Phillip Swagel

Jaime Marquez

Michael P. Leahy

John Ammer

Richard T. Freeman

Maurice Obstfeld

Prakash Loungani Mark Rush

William L. Helkie David H. Howard Jaime Marquez

Karen H. Johnson 